\title{
The nondepolarizing, normokalemic cardioplegia formulation adenosine-lidocaine (adenocaine) exerts anti-neutrophil effects by synergistic actions of its components
}

\author{
Weiwei Shi, MD, PhD, ${ }^{\mathrm{a}}$ Rong Jiang, MD, PhD, ${ }^{\mathrm{a}}$ Geoffrey P. Dobson, $\mathrm{PhD},{ }^{\mathrm{b}}$ Asger Granfeldt, $\mathrm{MD},{ }^{\mathrm{c}}$ and \\ Jakob Vinten-Johansen, $\mathrm{PhD}^{\mathrm{a}}$
}

Objective: A new strategy of normothermic cardioplegia based on the combination of adenosine and lidocaine (adenocaine; Hibernation Therapeutics Global Ltd, Kilquade, Ireland) achieves nondepolarized arrest at normokalemia. Both adenosine and lidocaine independently inhibit neutrophil (polymorphonuclear neutrophil; PMN) activity. However, whether adenocaine exerts greater anti-inflammatory effects is not known. We tested the hypothesis that adenocaine synergistically attenuates PMN functions.

Methods: Superoxide anion $\left(\mathrm{O}_{2}{ }^{-}\right)$generation: Isolated porcine $\mathrm{PMNs}$ were primed with cytochalasin $\mathrm{B}(5 \mu \mathrm{g} / \mathrm{mL})$ and activated by $\mathrm{N}$-formylmethionyl-leucyl-phenylalanine $(100 \mathrm{nM}) . \mathrm{O}_{2}^{-}$release was quantified using lucigeninenhanced chemiluminescence. Data were expressed as percent of stimulated control.

Results: Both adenosine and lidocaine alone inhibited $\mathrm{O}_{2}^{-}$production in a dose-dependent manner (adenosine reduced to $67 \% \pm 8.4 \%$ and $21 \% \pm 2.2 \%$ of maximal stimulation at 0.1 and $10 \mu \mathrm{mol} / \mathrm{L}$, respectively, lidocaine reduced to $57.9 \% \pm 18.6 \%$ and $28 \% \pm 5 \%$ at 10 and $100 \mu \mathrm{mol} / \mathrm{L}$, respectively). Adenocaine further reduced $\mathrm{O}_{2}^{-}$generation in a synergistic manner. In addition, adenosine alone $(0.1-10 \mu \mathrm{mol} / \mathrm{L})$ inhibited $\mathrm{O}_{2}^{-}$generation in primed but not activated PMNs, whereas lidocaine alone (1-100 $\mu \mathrm{mol} / \mathrm{L})$ inhibited $\mathrm{O}_{2}^{-}$release in both primed and activated PMNs. Adenocaine further reduced $\mathrm{O}_{2}^{-}$generation because of inhibition of both priming and activation stages. Both adenosine and lidocaine alone and adenocaine comparably inhibited platelet activating factor-induced CD11 b/c surface expression on PMNs (flow cytometry), but adenocaine further suppressed both CD18 expression (to $47.4 \% \pm 9.7 \%$ ) and PMN adherence (to $47.2 \% \pm 4.3 \%$ ) compared with adenosine and lidocaine alone. Transmigration of calcein-acetyoxymethyl-labeled PMNs through transwells seeded with cultured coronary artery endothelial cells was reduced comparably by adenosine (to $80.1 \% \pm 6.7 \%$ ) and adenocaine $(67.3 \% \pm 9.6 \%)$.

Conclusions: Adenocaine suppresses multiple PMN functions including $\mathrm{O}_{2}^{-}$generation, adhesion molecule expression, PMN adherence, and transmigration. In addition to inducing nondepolarized arrest, adenocaine cardioplegia may exert cardioprotection by inhibiting PMN-mediated inflammatory responses. (J Thorac Cardiovasc Surg 2012;143:1167-75)

Hyperkalemic cardioplegia has been widely used in cardiac surgery where elective cardiac arrest is achieved by depolarizing the myocyte membrane. However, hyperkalemic cardioplegia has several complications. Membrane depolarization by hyperkalemia is associated with a persistent ion transmembrane flow through sodium and calcium "window currents," causing intracellular sodium and calcium overload, energy exhaustion, arrhythmias, and cardiomyocyte and endothelial cell dysfunction and death. ${ }^{1}$ In

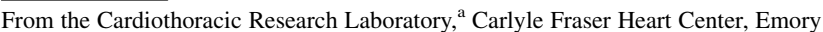
University, Atlanta, Ga; James Cook University, ${ }^{\mathrm{b}}$ Townsville, Queensland, Australia; and Department of Anesthesiology and Intensive Care Medicine, ${ }^{\mathrm{c}}$ Aarhus University Hospital, Aarhus, Denmark.

Disclosures: Authors have nothing to disclose with regard to commercial support.

Received for publication April 26, 2011; revisions received June 7, 2011; accepted for publication June 28, 2011; available ahead of print Nov 14, 2011.

Address for reprints: Jakob Vinten-Johansen, $\mathrm{PhD}$, Cardiothoracic Research Laboratory, Carlyle Fraser Heart Center, Emory University, 550 Peachtree Street NE, Atlanta, GA 30308-2225 (E-mail: jvinten@emory.edu).

$0022-5223 / \$ 36.00$

Copyright (C) 2012 by The American Association for Thoracic Surgery doi:10.1016/j.jtcvs.2011.06.045
}

inflammatory responses, the adherence of neutrophils to cardiomyocytes leads to depolarization of the myocyte, sodium influx, and cell death. ${ }^{2}$ An alternative approach to achieving elective cardiac arrest is to maintain the transmembrane potential in a polarized state, ${ }^{3,4}$ which clamps the ion channels in a "closed" state and thereby prevents subsequent cellular depolarization and the formation of the action potential. Thus, maintaining cardiomyocytes in a polarized state may avoid window currents, ionic imbalances, and subsequent consequences. The combination of adenosine and lidocaine arrests the heart in a polarized state without hyperkalemia. ${ }^{5,6}$ Adenosine also stimulates adenosine triphosphate-sensitive potassium channels by activation of the $A_{1}$ receptor. Lidocaine inhibits transmembrane depolarization by blocking sodium fast channels. The combination of adenosine and lidocaine in cardioplegia (adenocaine; Hibernation Therapeutics Global Ltd, Kilquade, Ireland) has been shown to successfully induce polarized arrest in isolated rat hearts ${ }^{4,6}$ and in canine hearts on cardiopulmonary bypass when delivered 


$$
\begin{aligned}
& \text { Abbreviations and Acronyms } \\
& \begin{aligned}
\text { AM } & =\text { acetyoxymethyl } \\
\text { Cyto B } & =\text { cytochalasin B } \\
\text { FBS } & =\text { fetal bovine serum } \\
\text { fMLP } & =\text { formylmethionyl-leucyl- } \\
& \text { phenylalanine } \\
\text { HBSS } & \text { Hank's buffered salt solution } \\
\text { IL } & =\text { interleukin } \\
\text { PAF } & =\text { platelet activating factor } \\
\text { PCAEC }= & \text { pig coronary arterial endothelial cell } \\
\text { PECGM } & \text { Porcine Endothelial Cell Growth } \\
& \text { Medium } \\
\text { PMN }= & \text { polymorphonuclear neutrophil } \\
\text { RLU } & =\text { relative light units } \\
\text { RPMI } & =\text { Roswell Park Memorial Institute } \\
\text { SEM } & =\text { standard error of the mean }
\end{aligned}
\end{aligned}
$$

normothermically or hypothermically. ${ }^{7}$ The concentrations of adenosine and lidocaine that achieve polarized arrest range from 200 and $500 \mu \mathrm{mol} / \mathrm{L}$, respectively, in isolated hearts using a crystalloid solution, ${ }^{4}$ to 400 and $750 \mu \mathrm{mol} /$ $\mathrm{L}$, respectively, in blood cardioplegia. ${ }^{7}$ However, adenocaine has also been used clinically at lower concentrations in moderately hyperkalemic blood cardioplegia in which the adenosine concentration is approximately $56 \mu \mathrm{mol} / \mathrm{L}$ and lidocaine is approximately $64 \mu \mathrm{mol} / \mathrm{L}^{8}$

The activation of polymorphonuclear neutrophils (PMNs) and the inflammatory response during cardiopulmonary bypass and cardioplegia likely contribute to post-cardioplegia dysfunction and adverse outcomes. ${ }^{9}$ Both adenosine ${ }^{10}$ and lidocaine ${ }^{11}$ individually exert anti-inflammatory properties. Adenosine attenuates PMN proinflammatory functions and reperfusion injury mainly through activation of $\mathrm{A}_{2}$ and possibly $\mathrm{A}_{3}$ receptors. ${ }^{10,12,13}$ Lidocaine has also been shown to inhibit the inflammatory response to reperfusion injury, although the mechanism is unclear. ${ }^{14}$ This study tested the hypothesis that the combination of adenosine and lidocaine (adenocaine) inhibits inflammatory functions of PMNs. In particular, we determined the lowest concentrations of components in adenocaine that potentially exerted anti-PMN effects.

\section{MATERIALS AND METHODS \\ Chemicals}

Chemicals used in this study were purchased from Sigma-Aldrich (St Louis, Mo) unless otherwise stated. All chemicals were prepared in double-distilled $\mathrm{H}_{2} \mathrm{O}$ or in dimethyl sulfoxide. In cases in which dimethyl sulfoxide was used, its concentration was maintained at less than $0.1 \%$ in solutions.

\section{Polymorphonuclear Neutrophil Isolation}

All animals received humane care in compliance with the "Guide for the Care and Use of Laboratory Animals" (available at: http://www.nap. edu/catalog/5140.html). PMNs were prepared using a protocol described previously. ${ }^{15}$ Briefly, peripheral blood $(20 \mathrm{~mL})$ was withdrawn from Yorkshire pigs using an arterial access and mixed with $10 \mathrm{~mL} 6 \%$ dextran and $4.5 \mathrm{~mL}$ anticoagulating buffer containing $1.6 \%$ citric acid and $2.5 \%$ sodium citrate. The blood sample was kept at room temperature for 40 minutes to sediment erythrocytes. The leukocyte-rich top layer was centrifuged at $400 \mathrm{~g}$ for 10 minutes at $4{ }^{\circ} \mathrm{C}$. The pellet was lysed for 20 seconds with 9 $\mathrm{mL}$ of sterile distilled water to remove red blood cells, followed by the addition of $3 \mathrm{~mL}$ of $0.6 \mathrm{~mol} / \mathrm{L} \mathrm{KCl}$ and $25 \mathrm{~mL}$ of Hank's buffered salt solution (HBSS) without $\mathrm{Ca}^{2+}$ and $\mathrm{Mg}^{2+}$ (Mediatech Inc, Manassas, Va). After another 10 minutes of centrifugation, the pellet was resuspended in $2 \mathrm{~mL}$ HBSS without $\mathrm{Ca}^{2+}$ and $\mathrm{Mg}^{2+}$, layered on the top of $3 \mathrm{~mL}$ of FicollPacque (GE Healthcare, Piscataway, NJ), and centrifuged at $400 \mathrm{~g}$ for 30 minutes at $4{ }^{\circ} \mathrm{C}$. The cell pellet was resuspended in ice-cold HBSS without $\mathrm{Ca}^{2+}$ and $\mathrm{Mg}^{2+}$. The cell number was counted. The final cell suspension contained $94 \%$ PMNs, and cell viability was $99 \%$ as determined by trypan blue exclusion. The PMNs were used within 4 hours after isolation.

\section{Endothelial Cell Culture}

Pig coronary arterial endothelial cells (PCAECs) used in adhesion and transmigration studies were purchased from Cell Applications Inc (San Diego, Calif). The cells were cultured as a monolayer in Porcine Endothelial Cell Growth Medium (PECGM; Cell Applications Inc) at $37^{\circ} \mathrm{C}$ in a humidified atmosphere of $95 \%$ air and $5 \% \mathrm{CO}_{2}$, and routinely split when cell density reached $90 \%$ to $100 \%$ confluence. The cells were used between passages 3 and 6 .

\section{Superoxide Production by Polymorphonuclear Neutrophils}

PMNs were primed with cytochalasin B (Cyto B; $5 \mu \mathrm{g} / \mathrm{mL}$, SigmaAldrich) for 5 minutes and activated by $\mathrm{N}$-formylmethionyl-leucyl-phenylalanine (fMLP; $100 \mathrm{nM}$ ). The samples were placed in a luminometer (Autolumat Plus LB953; Berthold Tech, Bad Wildbad, Germany). Lucigenin $(10 \mu \mathrm{mol} / \mathrm{L})$ in HBSS was automatically injected into each assay tube. Photon emissions from the samples were counted sequentially under atmospheric conditions. After background readings were taken, the lucigeninenhanced chemiluminescence reaction was read over 10 minutes, and the average background signal was subtracted. The superoxide anion $\left(\mathrm{O}_{2}^{-}\right)$release was expressed as relative light units (RLU) per $10^{6} \mathrm{PMNs}\left(\mathrm{RLU} / 10^{6}\right)$.

\section{Flow Cytometry}

Because of limited quality and availability of antibodies against porcine adhesion molecules, heparinized rat blood drawn from the carotid artery was used in flow cytometry studies. Arterial blood was anticoagulated with heparin; pretreated with adenosine, lidocaine, or adenocaine at the doses indicated (see "Results") for 5 minutes; and stimulated by $100 \mathrm{nM}$ platelet activating factor (PAF) for 15 minutes at room temperature. Then, $5 \mu \mathrm{L}$ of phycoerythrin-conjugated anti-CD11 b/c (OX-42; BD Pharmingen, San Diego, Calif) or $5 \mu \mathrm{L}$ of fluorescein isothiocyanateconjugated anti-CD18 (WT.3; BD Pharmingen) was incubated with 50 $\mu \mathrm{L}$ of blood sample for 15 minutes at room temperature in the dark. Red blood cells were lysed for 10 minutes using $2 \mathrm{~mL}$ of FACSlyse (BD Pharmingen). After centrifugation at $400 g$ for 5 minutes, cells were fixed with $1 \%$ paraformaldehyde and stored at $4{ }^{\circ} \mathrm{C}$. Data were acquired on a BD LSR II (BD Pharmingen). PMNs were identified by their forward scatter and side scatter profile using mouse anti-granulocyte antibody (His48; eBioscience Inc, San Diego, Calif). Autofluorescence was measured from cells stained with isotype control antibody. The expression of CD11b/c or CD18 was quantified using median fluorescence intensity with autofluorescence subtraction. The effect of adenosine, lidocaine, and adenocaine was calculated and normalized to a percent of basal expression (HBSS treated) versus the PAF-induced expression, and reported as means \pm standard error of the mean (SEM). 


\section{Polymorphonuclear Neutrophil Labeling}

Porcine PMNs $\left(1 \times 10^{7} / \mathrm{mL}\right)$ were resuspended in Roswell Park Memorial Institute (RPMI) 1640 (a type of leukocyte culture medium previously developed at Roswell Park Memorial Institute) containing 0.5\% fetal bovine serum (FBS) and labeled with calcein-acetyoxymethyl (AM) ( $1 \mu \mathrm{mol} / \mathrm{L}$; Molecular Probe, Carlsbad, Calif) in RPMI 1640 for 30 minutes at $37^{\circ} \mathrm{C}$. The cell pellets were obtained by centrifugation $(400 \mathrm{~g}$ ) for $5 \mathrm{~min}-$ utes at $4^{\circ} \mathrm{C}$ and washed with phosphate-buffered saline twice. After counting, the PMNs were resuspended in RPMI 1640 with $0.5 \%$ FBS for adherence and transmigration studies (see below).

\section{Polymorphonuclear Neutrophil Adherence Assay}

PCAECs were cultured in a 96-well cell culture microplate (Corning Inc, Corning, NY) until reaching $90 \%$ to $95 \%$ confluence. The PECGM was gently exchanged for RPMI 1640 with $0.5 \%$ FBS for serum starvation before adherence experiments. Calcein AM-labeled PMNs $\left(5 \times 10^{5} /\right.$ well $)$ were pretreated with given concentrations of adenosine, lidocaine, or adenocaine for 5 minutes and then stimulated by PAF (100 nM). Aliquots of PMN suspension were layered over the endothelial cells. After 15 minutes of incubation, the PMNs were gently aspirated from the endothelial cell monolayer. The microplate wells were carefully washed 3 times with prewarmed RPMI 1640 to remove nonadherent PMNs. An aliquot of PMNs was serially diluted, and fluorescence readings (absorbance of 494 $\mathrm{nm}$ and emission of $517 \mathrm{~nm}$ ) were obtained from Spectra MAX Gemini EM (Molecular Devices, Sunnyvale, Calif). Standard curves were plotted using the cell concentrations against the fluorescence to quantify the number of cells adhered. The effect of adenosine, lidocaine, and adenocaine was measured and normalized between the basal adherence and the PAFinduced adherence, and expressed as means \pm SEM.

\section{Polymorphonuclear Neutrophil Transmigration Assay}

Cell culture transwells (3.0- $\mu \mathrm{m}$ pore-size insert, polyester membrane, $6.5 \mathrm{~mm}$ dimension, Costar; Corning Inc) were rinsed in PECGM for 30 minutes in an incubator before use. One day before the transmigration assay, PCAECs $\left(2 \times 10^{5}\right)$ were seeded onto each transwell insert. After overnight culture, the PCAECs formed a confluent monolayer. The culture medium was changed to RPMI 1640 with $0.5 \%$ FBS for serum starvation. Calcein-AM labeled $10^{6}$ PMNs per well were added to the top chamber. Porcine interleukin (IL)-8 (10 nM; R\&D Systems, Minneapolis, Minn) was added to the lower chamber as chemoattractant. The transwell systems were incubated at $37^{\circ} \mathrm{C}$ for 1 hour, after which the inserts were removed and the fluorescence emitted from the lower chamber was measured using a Spectra MAX Gemini EM. The number of migrated PMNs was quantified using a similar protocol described in the adherence assay. IL-8-induced transmigration with the addition of vehicle, adenosine, lidocaine, or adenocaine was normalized against the basal transmigration.

\section{Statistical Analysis}

The effects of adenosine, lidocaine, or adenocaine (3-10 separate experiments in each assay) were expressed as a percent of the corresponding stimulated control. Values were presented as means \pm SEM. Group differences were analyzed using a 1-way analysis of variance. Where group differences were detected, post hoc Tukey's or Student-Newman-Keuls multiple comparison tests were performed to determine which groups differed.

\section{RESULTS \\ $\mathrm{O}_{2}^{-}$Production}

Cyto B is a widely used priming agent, whereas fMLP acts as an activator of PMNs. ${ }^{16}$ The resting PMNs demonstrated a low level of $\mathrm{O}_{2}^{-}$generation of less than 10
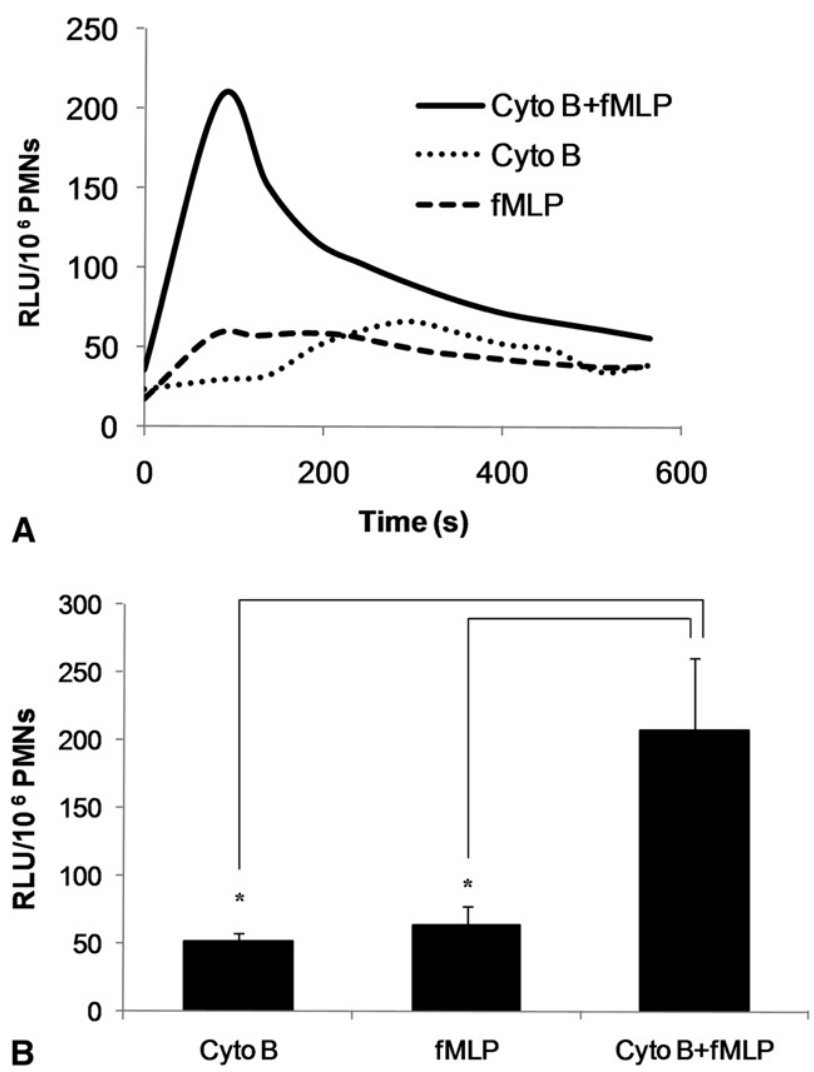

FIGURE 1. $\mathrm{O}_{2}^{-}$generation by cytochalasin $\mathrm{B}$ (Cyto B, $5 \mu \mathrm{g} / \mathrm{mL}$ ) and fMLP (100 nM). A, Time course of $\mathrm{O}_{2}^{-}$production from PMNs under different stimulatory conditions. Cyto B or fMLP alone induced only a mild $\mathrm{O}_{2}^{-}$release. The fully activated PMNs that were primed with Cyto B and subsequently activated by fMLP (Cyto $\mathrm{B}+\mathrm{fMLP}$ ) released $\mathrm{O}_{2}^{-}$in a burst pattern. $\mathrm{B}$, Summary of the maximal $\mathrm{O}_{2}^{-}$production in the presence of different stimulators. The $\mathrm{O}_{2}^{-}$generation was significantly enhanced in the Cyto B + fMLP group. ${ }^{*} P<.05$ versus Cyto B-primed and fMLPactivated PMNs. $P M N$, Polymorphonuclear neutrophil; $R L U$, relative light units; $f M L P$, formylmethionyl-leucyl-phenylalanine.

RLU $/ 10^{6}$ cells. The $\mathrm{O}_{2}^{-}$generation induced by Cyto $\mathrm{B}$ or fMLP alone was modest with a peak averaging $52 \pm 6$ RLU/10 $0^{6}$ cells $(\mathrm{n}=8)$ for Cyto $\mathrm{B}$ alone and $64 \pm 14$ RLU $/ 10^{6}$ cells $(\mathrm{n}=9)$ for fMLP alone (Figure $\left.1, A, B\right)$. In contrast, in the fully activated PMNs first primed by Cyto B $(5 \mu \mathrm{g} / \mathrm{mL})$ and subsequently activated by fMLP $(100$ $\mathrm{nM}), \mathrm{O}_{2}^{-}$was produced in a burst pattern (Figure 1, A) with a significantly higher peak $\mathrm{O}_{2}^{-}$release averaging $207 \pm 54$ RLU $/ 10^{6}$ cells $(\mathrm{n}=17$, Figure $1, B$ ).

The effect of adenosine and lidocaine was normalized to the maximal stimulation of PMNs by $5 \mu \mathrm{g} / \mathrm{mL}$ Cyto B plus $100 \mathrm{nM}$ fMLP after correcting for blank (HBSS alone). Superoxide dismutase $(0.1 \mathrm{mg} / \mathrm{mL})$ almost completely abolished the $\mathrm{O}_{2}^{-}$generation, confirming that the chemiluminescence signal was largely derived from $\mathrm{O}_{2}{ }^{-}$ (Figure 2, $A-C$ ). Adenosine and lidocaine alone inhibited $\mathrm{O}_{2}^{-}$production in a concentration-dependent manner (Figure 2, B,C);1 $1 \mu \mathrm{mol} / \mathrm{L}$ adenosine reduced the $\mathrm{O}_{2}^{-}$ 

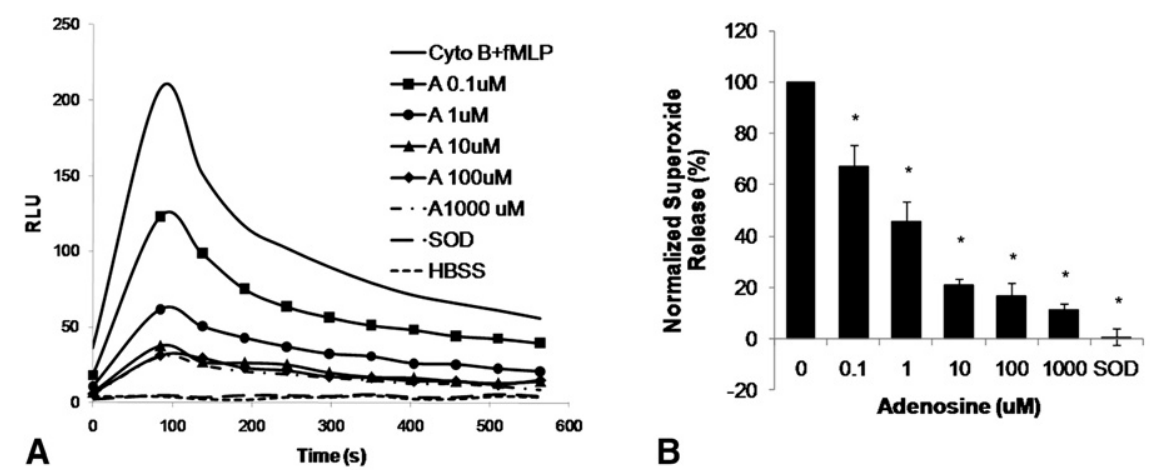

FIGURE 2. Effects of adenosine and lidocaine on $\mathrm{O}_{2}^{-}$generation in fully activated PMNs. A, Time course of $\mathrm{O}_{2}^{-}$generation from the fully activated PMNs. The untreated PMNs (HBSS) showed a small $\mathrm{O}_{2}^{-}$generation. Adenosine (A) suppressed $\mathrm{O}_{2}^{-}$production in a dose-dependent manner. Superoxide dismutase $(0.1 \mathrm{mg} / \mathrm{mL})$ almost abolished the $\mathrm{O}_{2}^{-}$production. $\mathrm{B}$, Concentration-dependent inhibition of $\mathrm{O}_{2}^{-}$generation by adenosine. The effect of adenosine was measured and normalized between the basal $\mathrm{O}_{2}^{-}$production from the untreated PMNs and the maximal $\mathrm{O}_{2}^{-}$generation induced by Cyto B and fMLP (mean \pm SEM). $* P<.05$ versus untreated PMNs. C, Lidocaine inhibited $\mathrm{O}_{2}^{-}$production in a dose-dependent manner. $* P<.05$ versus untreated PMNs. D, Shown is a summary of the effects of adenosine and lidocaine on $\mathrm{O}_{2}^{-}$production. Adenosine $(1$ or $10 \mu \mathrm{mol} / \mathrm{L})$ and lidocaine $(10,100,1000 \mu \mathrm{mol} / \mathrm{L})$ reduced $\mathrm{O}_{2}{ }^{-}$generation. ${ }^{*} P<.05$ versus untreated PMNs. The addition of $1 \mu \mathrm{mol} / \mathrm{L}$ adenosine to 100 or $1000 \mu \mathrm{mol} / \mathrm{L}$ lidocaine further suppressed the $\mathrm{O}_{2}{ }^{-}$generation. $+P<.05 \mathrm{vs}$ adenosine $(1 \mu \mathrm{mol} / \mathrm{L})$ group. In the presence of $10 \mu \mathrm{mol} / \mathrm{L}$ lidocaine, adenosine $(10 \mu \mathrm{mol} / \mathrm{L})$ provided further inhibition. $\dagger P<.05 \mathrm{vs} \mathrm{lidocaine}$ $(10 \mu \mathrm{mol} / \mathrm{L})$ group. Cyto B, Cytochalasin B; HBSS, Hanks' buffered salt soultion; $f M L P, \mathrm{~N}$-formylmethionyl-leucyl-phenylalanine; $P M N$, polymorphonuclear neutrophil; $S O D$, superoxide dismutase.

generation to $53.6 \% \pm 12.5 \%$ of stimulated control $(\mathrm{n}=3)$. Lidocaine $(10 \mu \mathrm{mol} / \mathrm{L}, 0 \mu \mathrm{mol} / \mathrm{L}$ adenosine $)$ alone decreased $\mathrm{O}_{2}^{-}$production to $57.9 \% \pm 18.6 \%$ of stimulated control (Figure $2, D ; \mathrm{n}=3, P<.05$ ). The addition of lidocaine (100 or $1000 \mu \mathrm{mol} / \mathrm{L})$ to $1 \mu \mathrm{mol} / \mathrm{L}$ adenosine further significantly suppressed the $\mathrm{O}_{2}^{-}$generation to $12.4 \% \pm$ $2.9 \%(\mathrm{n}=3)$ and $0.8 \% \pm 1.4 \%(\mathrm{n}=3)$, respectively, relative to $1 \mu \mathrm{mol} / \mathrm{L}$ adenosine alone. With the combination of $10 \mu \mathrm{mol} / \mathrm{L}$ adenosine and $10 \mu \mathrm{mol} / \mathrm{L}$ lidocaine, the $\mathrm{O}_{2}^{-}$release was further decreased to $18.3 \% \pm 1.9 \%(\mathrm{n}=3$, $P<.05)$. The greatest significant reduction in $\mathrm{O}_{2}^{-}$release was observed with $10 \mu \mathrm{mol} / \mathrm{L}$ adenosine and $100 \mu \mathrm{mol} / \mathrm{L}$ lidocaine. Therefore, the combination of $10 \mu \mathrm{mol} / \mathrm{L}$ adenosine and $100 \mu \mathrm{mol} / \mathrm{L}$ lidocaine exhibited synergistic inhibition of $\mathrm{O}_{2}^{-}$generation by activated PMNs.

To determine the individual effect of adenosine and lidocaine on $\mathrm{O}_{2}^{-} \mathrm{PMN}$ in primed versus activated stages, $\mathrm{PMNs}$ were stimulated with Cyto B (priming) or fMLP (activation) separately. Adenosine demonstrated a concentrationresponse relationship. As low as $0.1 \mu \mathrm{mol} / \mathrm{L}$ adenosine suppressed the Cyto $\mathrm{B}$-induced $\mathrm{O}_{2}^{-}$generation to $37.0 \% \pm$ $13.2 \%$ of stimulated control values (Figure $3, A ; \mathrm{n}=4$,
$P<.05$ vs Cyto B-treated PMNs). In contrast, there was no such concentration-response relationship demonstrated in activated only PMNs; a higher concentration of adenosine $(100 \mu \mathrm{mol} / \mathrm{L})$ was required to significantly inhibit the fMLPinduced $\mathrm{O}_{2}^{-}$production (Figure $3, A ; 73.5 \% \pm 11.4 \%$, $\mathrm{n}=5, P<.05$ vs fMLP-treated PMNs). However, lidocaine attenuated $\mathrm{O}_{2}^{-}$generation after both priming alone and activation alone in a concentration-response pattern (Figure 3, $B)$. Clear inhibition in either group was obtained with 10 $\mu \mathrm{mol} / \mathrm{L}$ lidocaine $(69.3 \% \pm 6.1 \%, \mathrm{n}=4, P<.05$ vs Cyto B-treated PMNs and 55.2\% $\pm 9.6 \%, \mathrm{n}=4, P<.05$ vs fMLP-treated PMNs, respectively). To simplify the subsequent studies, $50 \mu \mathrm{mol} / \mathrm{L}$ adenosine and $100 \mu \mathrm{mol} / \mathrm{L}$ lidocaine were chosen because these concentrations were effective in inhibiting $\mathrm{O}_{2}^{-}$generation in the present study and used in a previous in vivo study using a porcine model of left ventricular arrest and resuscitation. ${ }^{17}$ The Cyto B-induced $\mathrm{O}_{2}^{-}$production was reduced to $21.7 \% \pm 3.0 \%$ by $50 \mu \mathrm{mol} / \mathrm{L}$ adenosine and to $19.1 \% \pm 3.7 \%$ by 100 $\mu \mathrm{mol} / \mathrm{L}$ lidocaine (Figure 3, C; $\mathrm{n}=8, P<.05$ vs Cyto B-treated group). The combination of $50 \mu \mathrm{mol} / \mathrm{L}$ adenosine and $100 \mu \mathrm{mol} / \mathrm{L}$ lidocaine further decreased $\mathrm{O}_{2}^{-}$production 

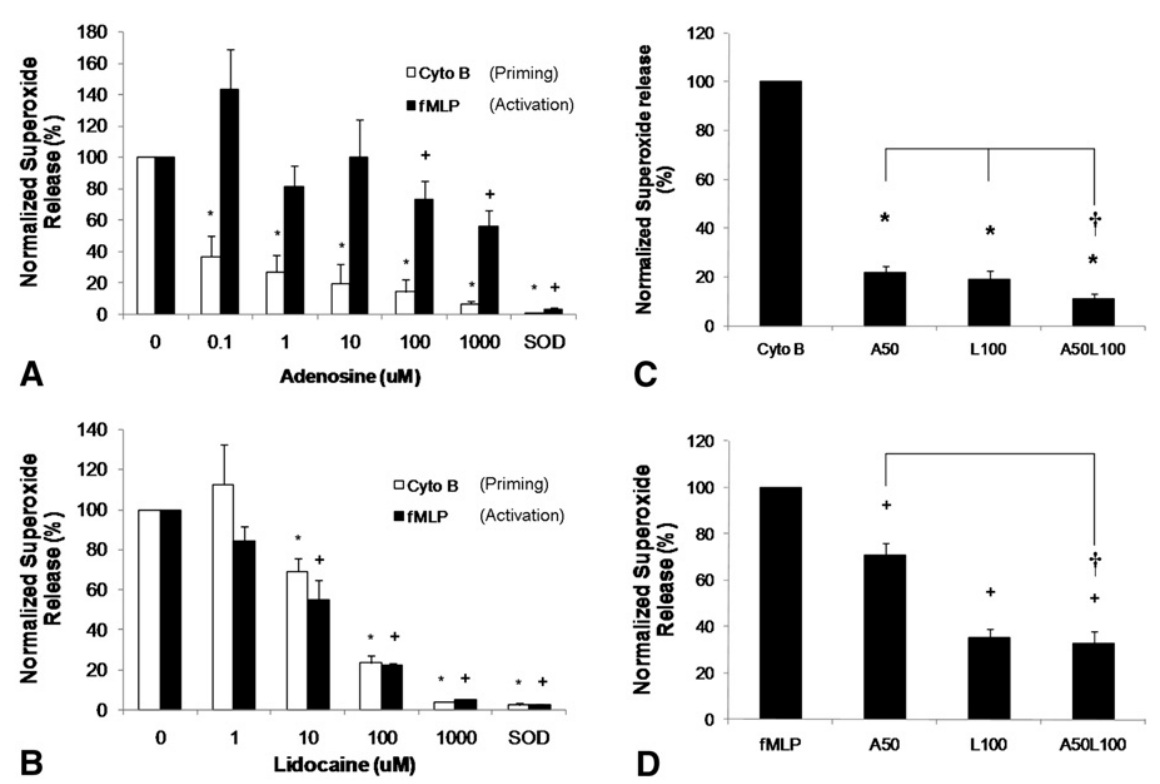

FIGURE 3. Summary of effects of adenosine and lidocaine on $\mathrm{O}_{2}^{-}$production by Cyto B and fMLP. A, Inhibition of the Cyto B-induced $\mathrm{O}_{2}^{-}$generation was seen with $0.1 \mu \mathrm{mol} / \mathrm{L}$ adenosine $\left({ }^{*} P<.05\right.$ vs Cyto B-treated PMNs), whereas $100 \mu \mathrm{mol} / \mathrm{L}$ adenosine significantly inhibited the fMLP-induced $\mathrm{O}_{2}{ }^{-}$ production $\left(+P<.05\right.$ vs fMLP-treated PMNs). B, Lidocaine had a similar effect on $\mathrm{O}_{2}^{-}$production induced by Cyto B or fMLP. A significant reduction of $\mathrm{O}_{2}^{-}$release from Cyto B-treated or fMLP-treated PMNs was evident with more than $10 \mu \mathrm{mol} / \mathrm{L}$ lidocaine, with an $80 \%$ reduction observed with 100 $\mu \mathrm{mol} / \mathrm{L}$ lidocaine $\left(* P<.05\right.$ vs Cyto B-treated PMNs and $+P<.05$ vs fMLP-treated PMNs, respectively). C, Cyto B-induced $\mathrm{O}_{2}^{-}$production was reduced to $21.7 \%$ by $50 \mu \mathrm{mol} / \mathrm{L}$ adenosine (A50) and to $19.1 \%$ by $100 \mu \mathrm{mol} / \mathrm{L}$ lidocaine (L100) ( $\mathrm{n}=8, * P<.05$ vs Cyto B-treated group). The combination of 50 $\mu \mathrm{mol} / \mathrm{L}$ adenosine and $100 \mu \mathrm{mol} / \mathrm{L}$ lidocaine (A50L100) further decreased $\mathrm{O}_{2}^{-}$production to $11.0 \%\left(\mathrm{n}=8, \dagger P<.05\right.$ vs A50 or L100). D, $\mathrm{O}_{2}^{-}$generation from activated PMNs (fMLP treated) was decreased to approximately 70\% by A50 and approximately 35\% by L100 (n $=7, * P<.05$ vs fMLP-treated group), whereas it was decreased further to approximately $33 \%$ of stimulated controls with the combination of A50L100 (n $=7, \dagger P<.05$ vs A50). $f M L P$, Formylmethionyl-leucyl-phenylalanine.

to $11.0 \% \pm 2.1 \%(\mathrm{n}=8, P<.05$ vs $50 \mu \mathrm{mol} / \mathrm{L}$ adenosine or $100 \mu \mathrm{mol} / \mathrm{L}$ lidocaine). The fMLP-induced $\mathrm{O}_{2}^{-}$generation was decreased to $71.0 \% \pm 5.2 \%$ by $50 \mu \mathrm{mol} / \mathrm{L}$ adenosine and to $35.1 \% \pm 3.7 \%$ by $100 \mu \mathrm{mol} / \mathrm{L}$ lidocaine (Figure 3, $D ; \mathrm{n}=7, P<.05$ vs fMLP-treated group). The combination of $50 \mu \mathrm{mol} / \mathrm{L}$ adenosine and $100 \mu \mathrm{mol} / \mathrm{L}$ lidocaine decreased $\mathrm{O}_{2}^{-}$production to $32.8 \% \pm 5.1 \%(\mathrm{n}=7, P>.05$ vs $100 \mu \mathrm{mol} / \mathrm{L}$ lidocaine, $P<.05$ vs $50 \mu \mathrm{mol} / \mathrm{L}$ adenosine).

\section{Polymorphonuclear Neutrophil CD11 and CD18 Expression}

Ischemia-reperfusion injury elevates surface expression of $\beta 2$ integrins on PMNs. The heterodimeric $\beta 2$ integrins contain 2 subunits with an $\alpha$ subunit (CD11a, b, or $\mathrm{c}$ ) and $\beta$ subunit (CD18). By using a phycoerythrin-labeled anti-CD11 b/c and a fluorescein isothiocyanate-labeled anti-CD18 antibody, we quantified the median fluorescence intensity of PMNs. Fifteen-minute incubation with PAF $(100 \mathrm{nM})$ in antibody-labeled PMNs increased the median fluorescence intensity of PMN CD11 b/c from $61.2 \pm 8.9$ to $94.2 \pm 6.7$ (Figure $4, A ; \mathrm{n}=7, P<.05$ ) and enhanced CD18 expression from $171.8 \pm 5.2$ to $216.2 \pm 7.9$ (Figure $4, B ; \mathrm{n}=7, P<.001$ ). Preincubation of the blood sample with $50 \mu \mathrm{mol} / \mathrm{L}$ adenosine (Figure $4, C$ ) before
PAF activation significantly reduced the CD11 b/c expression to $59.0 \% \pm 8.2 \%$ of control compared with PAFactivated PMN ( $\mathrm{n}=7, P<.05)$. Lidocaine at $100 \mu \mathrm{mol} / \mathrm{L}$ decreased the CD11 b/c expression to $71.4 \% \pm 6.3 \%$ (Figure $4, C ; \mathrm{n}=7, P<.05$ ) of stimulation control. The combination of adenosine and lidocaine at 50 and 100 $\mu \mathrm{mol} / \mathrm{L}$, respectively, tended to further reduce CD11 b/c expression to $48.2 \% \pm 10.3 \%$ of controls (Figure $4, C ; \mathrm{n}=7$, $P<.05$ ), but this was not significant relative to the 50 $\mu \mathrm{mol} / \mathrm{L}$ adenosine or the $100 \mu \mathrm{mol} / \mathrm{L}$ lidocaine group. Likewise, $50 \mu \mathrm{mol} / \mathrm{L}$ adenosine significantly inhibited the CD18 expression to $69.5 \% \pm 9.4 \%$ compared with PAF-activated PMN (Figure $4, D ; \mathrm{n}=7, P<.05$ ), whereas $100 \mu \mathrm{mol} / \mathrm{L} \mathrm{li}-$ docaine reduced the CD18 expression to $81.0 \% \pm 8.6 \%$ (Figure $4, D ; \mathrm{n}=7, P<.05$ ) of stimulation control. However, the combination of adenosine $(50 \mu \mathrm{mol} / \mathrm{L})$ and lidocaine $(100 \mu \mathrm{mol} / \mathrm{L})$ significantly further decreased the CD18 expression to $47.4 \% \pm 9.7 \%$ (Figure $4, D ; \mathrm{n}=7$, $P<.05)$ relative to identical concentrations of adenosine or lidocaine alone.

\section{Polymorphonuclear Neutrophil Adherence}

When unstimulated PMNs were added to the 96-well plate and incubated with endothelial cells for 15 minutes, 

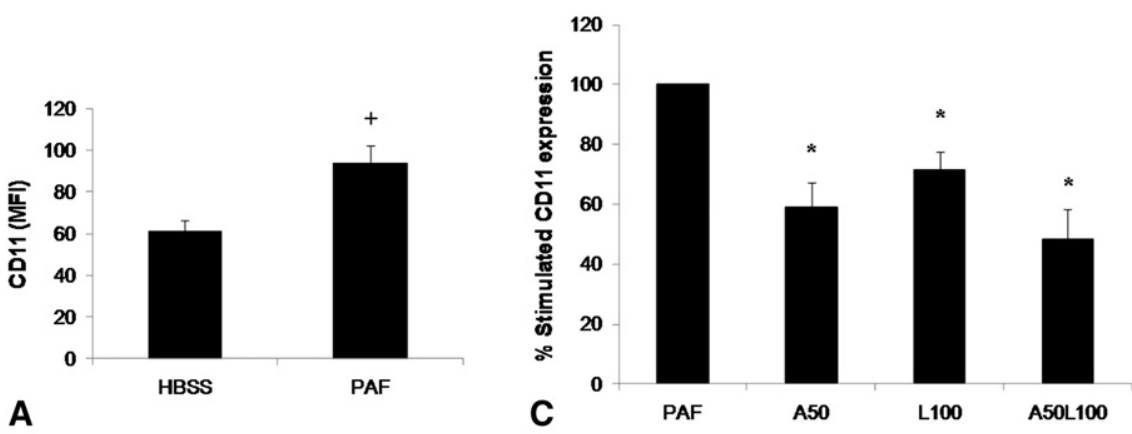

A
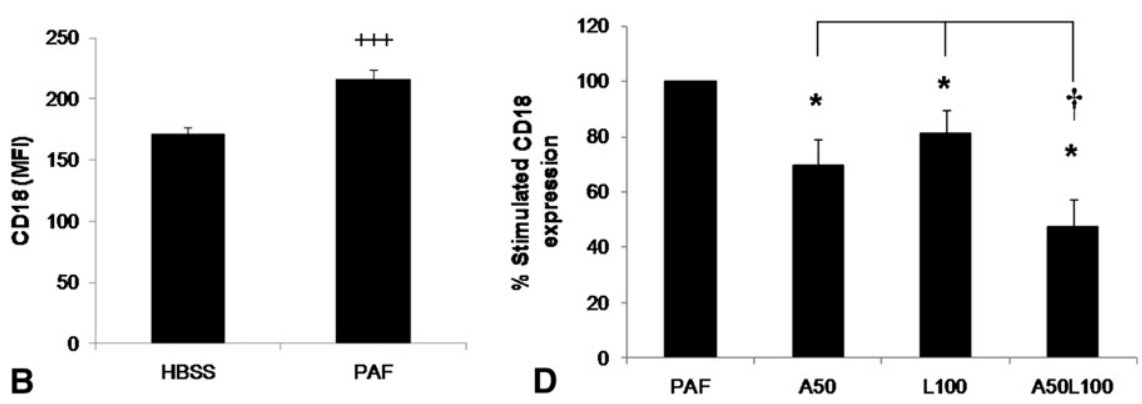

FIGURE 4. Decreased CD11/18 surface expression on PMNs by adenosine and lidocaine. A and B, The surface expressions of PMN CD11 b/c and CD18 were enhanced by PAF $(100 \mathrm{nM})(+P<.05,++P<.001)$. C, Pretreatment of blood with $50 \mu$ mol/L adenosine (A50) before PAF stimulation significantly reduced the CD11 b/c expression compared with PAF-activated PMN ( $\mathrm{n}=7, * P<.05$ ). Lidocaine at a concentration of $100 \mu$ mol/L (L100) decreased the CD11 b/c expression to $71.4 \% \pm 6.3 \%(\mathrm{n}=7, * P<.05)$ of stimulation control. The combination of $50 \mu \mathrm{mol} / \mathrm{L}$ adenosine and $100 \mu \mathrm{mol} / \mathrm{L}$ lidocaine (A50L100) further reduced the CD11 b/c expression $(\mathrm{n}=7, * P<.05)$, but the effect was not significant from adenosine or lidocaine alone. D, Both A50 and L100 significantly reduced the CD18 expression compared with PAF-activated PMN ( $\mathrm{n}=7$ each, $* P<.05)$. A50L100 further decreased CD18 expression $\left(\mathrm{n}=7,{ }^{*} P<.05\right)$, and the effect was significantly different from both adenosine and lidocaine (n $\left.=7, \dagger P<.05\right)$. $M F I$, Median fluorescence intensity; $P A F$, platelet activating factor; HBSS, Hank's buffered salt solution.

an average of $3.9 \times 10^{4}$ cells were observed to adhere to the endothelial surface. Activation of PMNs with $100 \mathrm{nM}$ PAF resulted in a near doubling of adherence to $7.5 \times 10^{4}$ cells (Figure 5, $A ; \mathrm{n}=19, P<.001$ ). Both adenosine (Figure 5, $B$ ) and lidocaine (Figure 5,C) alone inhibited PAF-induced PMN adherence to endothelial cells. As shown in Figure 5, $D$, preincubation of PMNs with $50 \mu \mathrm{mol} / \mathrm{L}$ adenosine before PAF activation significantly reduced the adherence to $71.6 \% \pm 5.4 \%$ compared with PAF-activated PMN (n $=8, P<.05$ ), whereas $100 \mu \mathrm{mol} / \mathrm{L}$ lidocaine alone decreased the adherence to $73.2 \% \pm 8.1 \%$ (Figure $5, D$; $\mathrm{n}=7, P<.05)$ of stimulation control. The combination of adenosine and lidocaine significantly further reduced the adherence to $47.2 \% \pm 4.3 \%$ (Figure $5, D ; \mathrm{n}=7$, $P<.05)$.

\section{Adenosine Inhibited Polymorphonuclear Neutrophil Transmigration Across Coronary Artery Endothelial Cells}

We tested the migration of PMN through PCAECs towards the chemoattractant IL- 8 contained in the lower chamber of the transwell. In the presence of IL-8 $(10 \mathrm{nM})$, the average number of PMNs that migrated across the endothelial cell layer increased from $16 \times 10^{4}$ (no IL-8) to $52 \times 10^{4}$ (Figure $6, A ; \mathrm{n}=6, P<.05$ ). After pretreatment with adenosine $(50 \mu \mathrm{mol} / \mathrm{L})$, transendothelial migration of PMNs was reduced to $80.1 \% \pm 6.7 \%$ of control PCAECs (Figure $6, B ; \mathrm{n}=6, P<.05)$. Lidocaine $(100 \mu \mathrm{mol} / \mathrm{L}) \mathrm{did}$ not significantly decrease the transmigration of PMNs (Figure $6, B ; 82.9 \% \pm 17.0 \%, \mathrm{n}=6, P>.05$ ) due in part to the variability around the mean value. The combination of $50 \mu \mathrm{mol} / \mathrm{L}$ adenosine and $100 \mu \mathrm{mol} / \mathrm{L}$ lidocaine did not significantly further reduce transmigration, although a small trend was observed (Figure $6, B ; 67.3 \% \pm 9.6 \%$, $\mathrm{n}=6, P>.05)$.

\section{DISCUSSION}

The results of the present study demonstrate the following: (1) Adenosine alone inhibits $\mathrm{PMN}_{2}^{-}$generation, CD11 and CD18 surface expression, adherence, and transmigration in vitro. In addition, adenosine decreases superoxide production likely through inhibiting the priming process, whereas lidocaine inhibits both priming and activation. (2) Lidocaine alone did not significantly reduce PMN transmigration because of a larger variability around the average, whereas adenosine significantly inhibited transmigration. (3) Adenocaine exerts greater inhibition of PMN $\mathrm{O}_{2}^{-}$generation, $\mathrm{CD} 18$ surface expression, and adherence to endothelial cells when compared with adenosine or lidocaine alone. Adenocaine inhibited $\mathrm{O}_{2}^{-}$in both primed and 

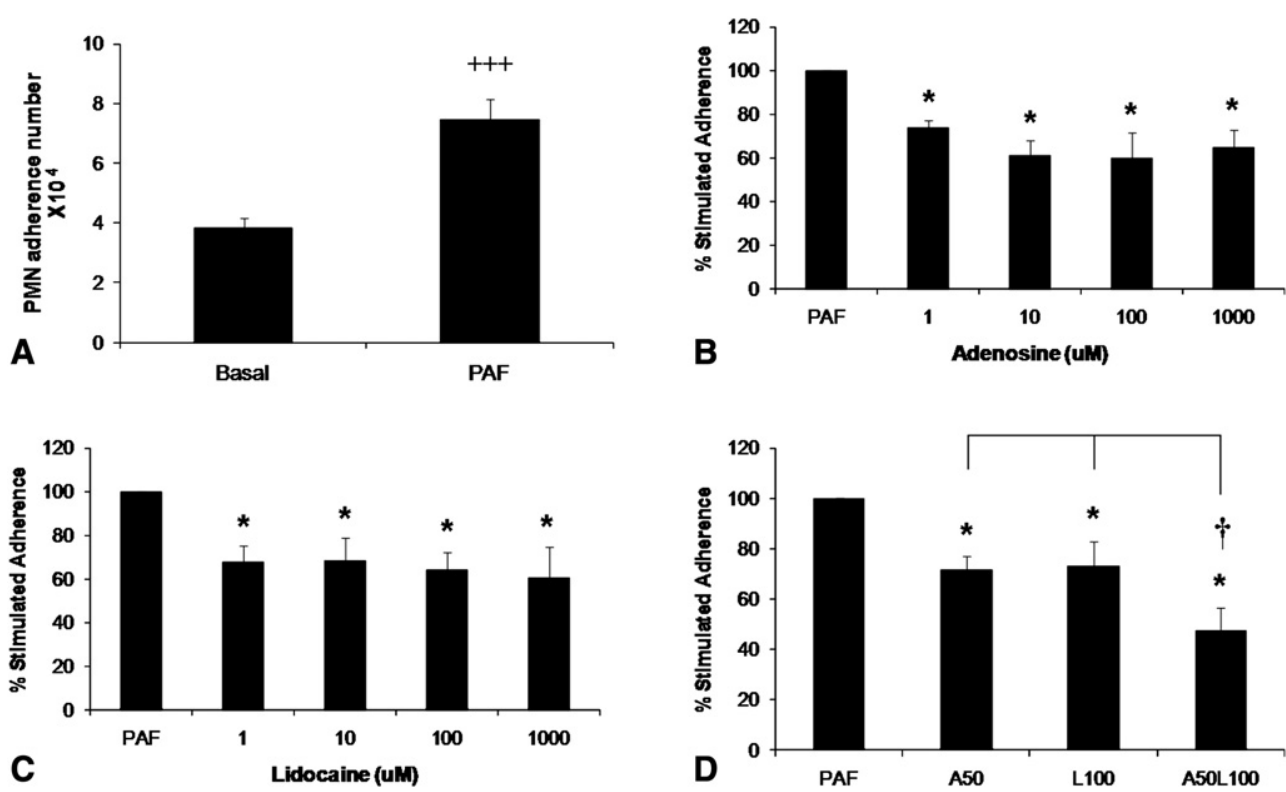

FIGURE 5. Reduced PMN adherence by adenosine and lidocaine. A, Calcein AM-labeled PMNs $\left(5 \times 10^{5} /\right.$ well) were layered over the confluent PCAECs. PAF $(100 \mathrm{nM})$ increased adherence of PMNs $(\mathrm{n}=19,+++P<.001)$. B, Pre-exposure of PMNs to adenosine reduced adherence. The effect of adenosine was measured and normalized between the basal adherence and the PAF-induced $(100 \mathrm{nM})$ adherence, and described as mean \pm SEM. Maximal activation was reached at $100 \mu \mathrm{mol} / \mathrm{L}$ with no change thereafter. $* P<.05$ versus PAF-induced PMN adherence. C, Inhibition of PMN adherence with lidocaine was observed at $1 \mu \mathrm{mol} / \mathrm{L}$, with modest inhibition thereafter $\left(\mathrm{n}=6,{ }^{*} P<.05\right.$ vs PAF-induced PMN adherence). D, The combination of adenosine $(50 \mu \mathrm{mol} / \mathrm{L}, \mathrm{A} 50)$ and lidocaine $(100 \mu \mathrm{mol} / \mathrm{L}, \mathrm{L} 100)$ additively inhibited PMN adherence. Adenosine and lidocaine both reduced PMN adherence, but adherence was further reduced by the combination of adenosine and lidocaine (A50L100) ( $\mathrm{n}=7, * P<.05$ vs PAF-treated PMNs, $\dagger P<.05$ vs A50 or L100-pretreated PMNs). PAF, Platelet activating factor; $P M N$, polymorphonuclear neutrophil.

fully activated PMNs. The lowest effective concentrations of adenosine averaged $50 \mu \mathrm{mol} / \mathrm{L}$ and lowest effective concentration of lidocaine averaged $100 \mu \mathrm{mol} / \mathrm{L}$. These concentrations are lower than the concentrations of adenosine and lidocaine that have been used in experimental studies used in isolated rat hearts ${ }^{4}$ and canine cardiopulmonary bypass model, ${ }^{7}$ and are similar to concentrations used in a clinical study in which adenocaine was used in nonarresting concentrations in moderately hyperkalemic blood cardioplegia. ${ }^{8}$ Thus, adenocaine suppresses PMN activation and other functions to a greater extent than each component drug alone. The beneficial effects reported by O'Rullian and colleagues ${ }^{8}$ in a high-risk patient may, in part, be derived from inhibition of inflammatory responses to cardiopulmonary bypass.

Adenosine and lidocaine alone have been shown to exert anti-inflammatory effects. Adenosine inhibits PMN activation through $\mathrm{A}_{2 \mathrm{a}}$ receptors. $\mathrm{A}_{2 \mathrm{a}}$ receptor stimulation attenuates PMN-induced coronary endothelial injury by reducing $\mathrm{O}_{2}^{-}$generation and adherence. ${ }^{15}$ In addition to blocking $\mathrm{Na}^{+}$ fast channels, lidocaine also affects $\mathrm{K}^{+}$channels ( $\mathrm{G}$ proteingated inwardly rectifying $\mathrm{K}^{+}$channels and 2-pore domain $\mathrm{K}^{+}$channels ${ }^{18,19}$ ) and vanilloid receptor TRPV1 channels. In addition to ion channel modulation, recent studies show that lidocaine can inhibit inflammation. As shown in the present study, lidocaine suppresses the generation of oxygen free radical species ${ }^{20}$ and attenuates the release of proinflammatory cytokines (IL-1 $\beta, \mathrm{IL}-8) .{ }^{21}$ Lidocaine has also been reported to reduce leukocyte adhesion ${ }^{22}$ and transmigration, ${ }^{23}$ again consistent with the results of the present study. Some of these effects are not due to $\mathrm{Na}^{+}$channel inhibition, because the $\mathrm{EC}_{50}$ of certain effects are in the nanomolar range, which is less than the $\mathrm{EC}_{50}$ for $\mathrm{Na}^{+}$channel blockade $(50-100 \mu \mathrm{mol} / \mathrm{L}) .{ }^{11}$ The mechanisms underlying these anti-inflammatory characteristics are not yet well understood. Lidocaine inhibits lipopolysaccharide-induced priming and NADPH oxidase assembly through suppression of cytochrome b558. ${ }^{24}$ Another study suggests that lidocaine can reduce $\mathrm{O}_{2}^{-}$generation through inhibiting p47 translocation. ${ }^{20}$

$\mathrm{O}_{2}^{-}$generation was induced by stimulating PMNs with Cyto B (primer) and fMLP (activator). Cyto B is a cytoskeleton disassembling toxin that increases the PMN response to other stimuli, such as PAF and fMLP, ${ }^{25}$ and is widely used as a priming agent. The bacterial peptide fMLP is a strong leukocyte chemoattractant and activator agent. Cyto $\mathrm{B}$ or fMLP alone induced a small $\mathrm{O}_{2}^{-}$production, which is in agreement with previous studies showing that full activation of PMN requires both priming and activating processes. ${ }^{16}$ The sequential use of Cyto B and fMLP simulated the priming that occurs with some cytokines, and subsequent activation by interaction with the vascular 

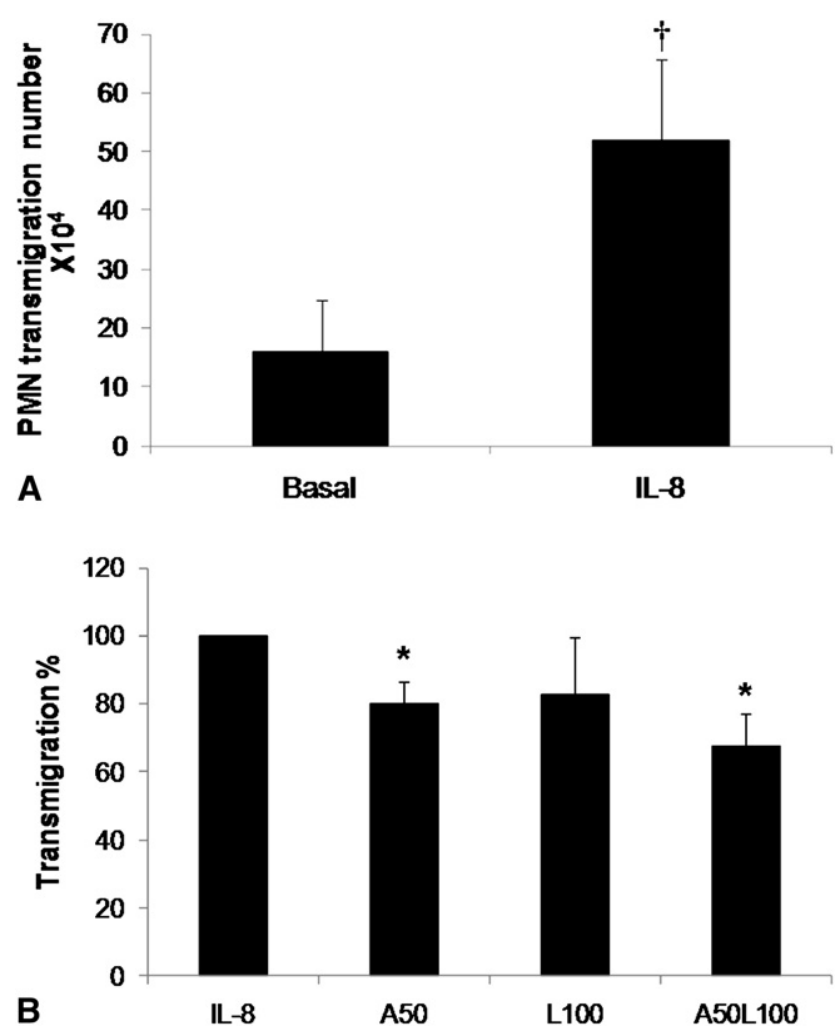

FIGURE 6. Reduced PMN transmigration by adenosine. A, IL-8 (10 nM) increased the number of migrated PMNs $(\mathrm{n}=6, \uparrow P<.05$ vs untreated PMNs). B, The effect of adenosine and lidocaine on transmigration. Data were normalized between the basal migration and the IL-8-induced migration. Adenosine $(50 \mu \mathrm{mol} / \mathrm{L}$, A50) significantly reduced the migration ( $\mathrm{n}=6, * P<.05$ vs IL-8-treated group), whereas lidocaine $(100 \mu \mathrm{mol} / \mathrm{L}$, L100) only tended to inhibit migration $(P>.05)$. The combination of adenosine and lidocaine (A50L100) did not significantly reduce transmigration compared with the adenosine alone group. $I L$, Interleukin; $P M N$, polymorphonuclear neutrophil.

endothelium. In the present study, we primed the isolated PMNs with Cyto B and then activated with fMLP to induce a peak oxidative burst as would be found in vivo. We found that both adenosine and lidocaine alone inhibited Cyto B-primed and fMLP-activated $\mathrm{O}_{2}^{-}$generation. The combination of adenosine and lidocaine in adenocaine provided further inhibition compared with adenosine or lidocaine alone. This finding suggests that adenosine and lidocaine work in a synergistic manner in adenocaine.

Adenosine has been reported to diminish the priming of human PMN induced by PAF rather than tumor necrosis factor- $\alpha .{ }^{26}$ An interesting finding in our study is that adenosine as low as $0.1 \mu \mathrm{mol} / \mathrm{L}$ significantly inhibited Cyto $\mathrm{B}$-induced $\mathrm{O}_{2}^{-}$generation, but only at a high concentration (100 $\mu \mathrm{mol} / \mathrm{L})$ can adenosine significantly reduce fMLP-induced $\mathrm{O}_{2}^{-}$production. The different responses indicate that adenosine may predominantly target certain types of priming processes. The priming of PMNs can also be blocked by lidocaine. Pretreatment of PMNs with lidocaine inhibits priming induced by lipopolysaccharide, PAF, or lysophosphatidic acid. ${ }^{23,24,27}$ In our study, lidocaine reduced the stimulatory effects of Cyto B and fMLP in a concentration-response pattern, suggesting lidocaine may target both priming and activating processes. Adenocaine effectively suppressed the effect of both priming (Cyto B) and activation (fMLP), which may reflect the predominance of lidocaine on both processes.

Adhesion molecule expression is one of the principle consequences of PMN priming ${ }^{16}$ and is another important event occurring in the early phase of reperfusion injury. ${ }^{9}$ Our data show that PAF-induced CD11 and CD18 surface expression was inhibited by adenosine and lidocaine alone, but that adenocaine further suppressed CD18 expression.

Vascular endothelial cells are key players in the inflammatory response to ischemia-reperfusion. ${ }^{28}$ The localization and recruitment of blood leukocytes to inflammatory tissues are endothelial-dependent events and critical responses to inflammation. ${ }^{28}$ Adenosine reduces the adherence of fMLP-stimulated PMN on cultured human umbilical vein endothelial cells ${ }^{29}$ and PAF-induced adherence of PMN to endothelial layer of isolated canine coronary artery segments. ${ }^{15}$ Lidocaine at plasma concentrations in the range of clinical practice reduces leukocyte adhesion to artificial materials ${ }^{30}$ and blood vessels. ${ }^{22}$ Our results are consistent with these previous studies. However, the combination of adenosine and lidocaine in adenocaine at the concentrations tested further decreased PAF-induced PMN CD18 expression and adherence, suggesting multifocal mechanisms in its anti-inflammatory effects.

The migration of PMN across endothelial layer is a critical event that occurs during ischemia-reperfusion injury. Adenosine diminishes ischemia-reperfusion-induced leukocyte extravasation in small intestine. ${ }^{31}$ We demonstrated that adenosine $A_{2}$ receptor activation significantly decreases PMN accumulation in the non-necrotic area at risk tissue in heart. ${ }^{13}$ In agreement, the current study suggests that adenosine decreased IL-8-induced PMN migration across the cultured coronary endothelial cells. Lidocaine reduces leukocyte migration in many in vivo studies. $^{22,32}$ In our study, although lidocaine tended to attenuate PMN transmigration, the effect is not significant. In agreement, adenocaine did not provide further inhibition compared with adenosine alone.

\section{CONCLUSIONS}

Compared with adenosine and lidocaine alone, adenocaine exerts greater inhibitory effects on PMN activities by reducing $\mathrm{O}_{2}^{-}$production, $\mathrm{CD} 18$ surface expression, and PMN adherence to vascular endothelium to a greater extent. These inhibitory effects can be exerted by adenocaine at lower concentrations of either component drug alone. Transmigration is also inhibited by adenocaine, 
although the effect is not significantly greater than that of adenosine alone. The concentrations that exerted antiinflammatory effects in the present study were similar to those used in a clinical study on adenocaine in cardiac surgery ${ }^{8}$ but lower than those proposed to arrest the heart in a polarized state without hyperkalemia. ${ }^{4,6}$ This lower, nonarresting dose of adenocaine may be effective in reducing the inflammatory responses to cardiopulmonary bypass and ischemia-reperfusion in moderately hyperkalemic cardioplegia. Lidocaine as a local anesthetic has longer lasting effects on $\mathrm{Na}^{+}$channels and cellular membrane excitability, whereas adenosine has a short half-life in vivo because of rapid deamination by plasma adenosine deaminase. The longer-lasting effects of lidocaine might contribute to the synergistic actions of adenocaine over adenosine alone. The cardioprotection afforded by adenocaine may go beyond the advantages of polarized arrest on reducing oxygen demands and stabilizing electrical excitability to include exerting anti-PMN effects at relatively low, nonarresting concentrations, which may be important in attenuating the inflammatory response to both ischemia-reperfusion and cardiopulmonary bypass. Future studies are required to determine whether adenocaine exerts anti-PMN and other anti-inflammatory effects in clinical cardioplegia, and if such effects are exerted, whether these effects translated to better clinical outcomes.

The authors thank the Carlyle Fraser Heart Center of Emory University Hospital Midtown for continued support of the Cardiothoracic Research Laboratory.

\section{References}

1. Damiano RJ Jr. The electrophysiology of ischemia and cardioplegia: implications for myocardial protection. J Card Surg. 1995;10(4 Suppl):445-53.

2. Ward CA, Bazzazi H, Clark RB, Nygren A, Giles WR. Actions of emigrated neutrophils on $\mathrm{Na}^{+}$and $\mathrm{K}^{+}$currents in rat ventricular myocytes. Prog Biophys Mol Biol. 2006;90:249-69.

3. Chambers DJ. Polarization and myocardial protection. Curr Opin Cardiol. 1999; 14:495-500.

4. Dobson GP, Jones MW. Adenosine and lidocaine: a new concept in nondepolarizing surgical myocardial arrest, protection, and preservation. J Thorac Cardiovasc Surg. 2004;127:794-805.

5. Dobson GP. Membrane polarity: a target for myocardial protection and reduced inflammation in adult and pediatric cardiothoracic surgery. J Thorac Cardiovasc Surg. 2010;140:1213-7.

6. Sloots KL, Dobson GP. Normokalemic adenosine-lidocaine cardioplegia: importance of maintaining a polarized myocardium for optimal arrest and reanimation. J Thorac Cardiovasc Surg. 2010;139:1576-86.

7. Corvera JS, Kin H, Dobson GP, Kerendi F, Halkos ME, Katzmark S, et al. Polarized arrest with warm or cold adenosine/lidocaine blood cardioplegia is equivalent to hypothermic potassium blood cardioplegia. J Thorac Cardiovasc Surg. 2005;129:599-606

8. O'Rullian JJ, Clayson SE, Peragallo R. Excellent outcomes in a case of complex re-do surgery requiring prolonged cardioplegia using a new cardioprotective approach: Adenocaine. J Extra Corpor Technol. 2008;40:203-5.

9. Vinten-Johansen J. Involvement of neutrophils in the pathogenesis of lethal myocardial reperfusion injury. Cardiovasc Res. 2004;61:481-97.
10. Cronstein BN. Adenosine, an endogenous anti-inflammatory agent. J Appl Physiol. 1994;76:5-13.

11. Cassuto J, Sinclair R, Bonderovic M. Anti-inflammatory properties of local anesthetics and their present and potential clinical implications. Acta Anaesthesiol Scand. 2006;50:265-82.

12. Jordan JE, Thourani VH, Auchampach JA, Robinson JA, Wang NP, VintenJohansen $\mathrm{J} . \mathrm{A}_{3}$ adenosine receptor activation attenuates neutrophil function and neutrophil-mediated reperfusion injury. Am J Physiol. 1999;277(5 Pt 2): H1895-905.

13. Jordan JE, Zhao ZQ, Sato H, Taft S, Vinten-Johansen J. Adenosine $A_{2}$ receptor activation attenuates reperfusion injury by inhibiting neutrophil accumulation, superoxide generation and coronary endothelial adherence. J Pharmacol Exp Ther. 1997;280:301-9.

14. Eskitascioglu T, Karaci S, Canoz O, Kilic E, Gunay GK. The impact of lidocaine on flap survival following reperfusion injury. J Surg Res. 2011;167:323-8.

15. Zhao ZQ, Sato H, Williams MW, Fernandez AZ, Vinten-Johansen J. Adenosine A2-receptor activation inhibits neutrophil-mediated injury to coronary endothelium. Am J Physiol. 1996;271(4 Pt 2):H1456-64.

16. Condliffe AM, Kitchen E, Chilvers ER. Neutrophil priming: pathophysiological consequences and underlying mechanisms. Clin Sci (Lond). 1998;94:461-71.

17. Granfeldt A, Shi W, Schmarkey LS, Jiang R, Bone CC, Wogensen L, et al. The combination of adenosine and lidocaine (Adenocaine) improves postresuscitation cardiac function following cardiac arrest. Circulation. 2010;122(Meeting Abstracts):A68

18. Zhou W, Arrabit C, Choe S, Slesinger PA. Mechanism underlying bupivacaine inhibition of $\mathrm{G}$ protein-gated inwardly rectifying $\mathrm{K}^{+}$channels. Proc Natl Acad Sci U S A. 2001;98:6482-7.

19. Kindler $\mathrm{CH}$, Yost CS. Two-pore domain potassium channels: new sites of local anesthetic action and toxicity. Reg Anesth Pain Med. 2005;30:260-74.

20. Arakawa K, Takahashi H, Nakagawa S, Ogawa S. The effects of lidocaine on superoxide production and $\mathrm{p} 47$ Phox translocation in opsonized zymosan-activated neutrophils. Anesth Analg. 2001;93:1501-6.

21. Lahav M, Levite M, Bassani L, Lang A, Fidder H, Tal R, et al. Lidocaine inhibits secretion of IL-8 and IL-1beta and stimulates secretion of IL-1 receptor antagonist by epithelial cells. Clin Exp Immunol. 2002;127:226-33.

22. MacGregor RR, Thorner RE, Wright DM. Lidocaine inhibits granulocyte adherence and prevents granulocyte delivery to inflammatory sites. Blood. 1980;56 203-9.

23. Fischer LG, Bremer M, Coleman EJ, Conrad B, Krumm B, Gross A, et al. Local anesthetics attenuate lysophosphatidic acid-induced priming in human neutrophils. Anesth Analg. 2001;92:1041-7.

24. Jinnouchi A, Aida Y, Nozoe K, Maeda K, Pabst MJ. Local anesthetics inhibit priming of neutrophils by lipopolysaccharide for enhanced release of superoxide: suppression of cytochrome b558 expression by disparate mechanisms. J Leukoc Biol. 2005;78:1356-65.

25. Bylund J, Pellme S, Fu H, Mellqvist U-H, Hellstrand K, Karlsson A, et al. Cytochalasin B triggers a novel pertussis toxin sensitive pathway in TNF-alpha primed neutrophils. BMC Cell Biology. 2004;5:21.

26. Stewart AG, Harris T. Adenosine inhibits platelet-activating factor, but not tumor necrosis factor-alpha-induced priming of human neutrophils. Immunology. 1993; 78:152-8.

27. Hollmann MW, Gross A, Jelacin N, Durieux ME. Local anesthetic effects on priming and activation of human neutrophils. Anesthesiology. 2001;95:113-22.

28. Rao RM, Yang L, Garcia-Cardena G, Luscinskas FW. Endothelial-dependent mechanisms of leukocyte recruitment to the vascular wall. Circ Res. 2007;101: 234-47.

29. Cronstein BN, Levin RI, Belanoff J, Weissmann G, Hirschhorn R. Adenosine: an endogenous inhibitor of neutrophil-mediated injury to endothelial cells. J Clin Invest. 1986;78:760-70.

30. Schiffer CA, Sanel FT, Young VB, Aisner J. Reversal of granulocyte adherence to nylon fibers using local anesthetic agents: possible application to filtration leukapheresis. Blood. 1977;50:213-25.

31. Grisham MB, Hernandez LA, Granger DN. Adenosine inhibits ischemiareperfusion-induced leukocyte adherence and extravasation. Am J Physiol. 1989;257(5 Pt 2):H1334-9.

32. McCafferty DM, Sharkey KA, Wallace JL. Beneficial effects of local or systemic lidocaine in experimental colitis. Am J Physiol. 1994;266(4 Pt 1):G560-7. 